\title{
On complex archaeologies: Conceptualising social complexity and its potential for archaeology
}

\section{Dries Daems ${ }^{1}$}

\begin{abstract}
This paper surveys a number of approaches in complex systems thinking and their relevance for applications in the field of archaeology. It focuses in particular on the fundamental role of social interactions and information transmission as constituent elements for the development of organizational complexity on a community level. Given the impossibility of direct observations of these constituent interactions and practices, it is then outlined how this theoretical model can be applied on the material remains found in the archaeological record. It is discussed how material surroundings - including architectural structures and material objects - are used to shape and structure social interactions and practices in various ways. It is shown how complex organizational structures develop through underlying mechanisms of change such as diversification, connectivity and standardization, and how these can be applied in archaeological case studies. The presented framework will thus show how structures of social organisation and development of social complexity can be inferred from the archaeological record.
\end{abstract}

\section{Keywords}

social complexity, social interaction, archaeological theory, material complexity, community formation

\section{Introduction}

This paper grew out of contributions to the sessions 'Evolution of Cultural Complexity' at the Conference of Complex Systems in Cancun and Thessaloniki, focused on questions regarding the definition, measurement and breakdown of sociocultural complexity. The wide range of scientific disciplines present at the session is testimony to the various ways this important topic can be approached. The goal of this paper is to offer insight into what archaeology might bring to the table. Focus will be on the development of social complexity centred on social interactions as fundamental components of human societies. This paper will highlight how complex organizational structures can emerge out of social interactions, and discuss how this process can be studied archaeologically.

\section{Social Complexity in Archaeology}

Complex systems thinking emphasizes non-deterministic and non-linear behaviour, interactive interdependencies among system components, feedback loops, and complex behaviour emerging from simple interactions (Lewin, 1992; Mitchell, 2009). The study of complex social systems particularly focuses on social interactions generating complex organizational structures (Freeberg, Dunbar, and Ord, 2012).

Concepts and methods from complex systems thinking have increasingly started to take off in archaeology as a way to deal with the complex nature of the archaeological record generated by life in the past (Bentley and Maschner, 2003; Chapman, 2003, Kohring and Wynne-Jones, 2007, Turchin et al., 2017). To discuss all of these approaches would fall beyond the scope of this paper. Focus will be on the nexus between social interaction and complexity, and the development of organizational complexity in community formation.

Broadly defined, community formation entails the development of collective action measures to mobilize a group towards a common goal (Axelrod, 1984, Blanton and Fargher, 2016). People may initiate collective action for a variety of reasons, but often these are related to the material conditions of human existence, i.e. demographical, ecological, technological, and economic factors, as these relate to the most basic human needs in production of subsistence and the reproduction of human life (Sanderson, 1999). Collective action driven by material conditions constitutes the basic platform for community formation to develop, as a common plane upon which day-to-day activities, interactions, and socialization take place (Smejda and Baumanova, 2015).

To cooperate, people need to interact. Social interaction occurs when two or more people create an episode of mutual awareness supplemented by transmission of information (Turner, 2003). Information transmission is not merely a "like-for-like" process, but has important multiplicative effects in generating novelty and innovation (Bettencourt, Lobo, and Strumsky, 2007). Complex social systems develop when individuals frequently interact in different contexts

\footnotetext{
${ }^{1}$ Sagalassos Project (Leuven, Belgium) and Suna \& Inan Kıraç Research Centre for Mediterranean Civilizations (Antalya, Turkey)

\section{Corresponding author:}

Daems Dries, Sagalassos Archaeological Research Project, Department of Archaeology, Blijde-Inkomststraat 21 - bus 3313, University of Leuven, Belgium

Email: dries.daems@kuleuven.be
} 
with many different individuals, often repeatedly many of the same people over time (Freeberg et al., 2012, p.1787). It has therefore been argued that the origins of increasing social complexity lie in growing community sizes and an exponential increase in (potential) social interactions (Dubreuil, 2010, Fletcher, 1995; Johnson, 1982). But how does the multiplicative effect of social interaction come to be?

One approach is to conceptualize communities as 'social reactors', entailing increased face-to-face interactions induced by population growth and aggregation - stimulating innovation and societal changes (Bettencourt, 2013; S. Ortman, Cabaniss, Sturm, and Bettencourt, 2015; S. G. Ortman et al., 2016). The central notion is that when a greater amount of people is more closely concentrated, social learning and knowledge transfers can take place more efficiently. Interactions can take place more frequently in highly clustered networks and are affected by more rapid feedback loops, thus decreasing lag time in the transfer of information.

Emergent effects generated by social reactors are community formation, socio-economic growth, and scalar stress. Developments on a social and economic plane via the first two are not limitless, but delineated by the latter, which is caused by limits to human information processing (Johnson, 1982). These form biological limits to group sizes by inducing group fission (Dunbar, 1993). Human groups can, however, circumvent these limits and "self-organize to better process socially transmitted information and more effectively make decisions" (Auban, Martin, and Barton, 2013 p. 56; see also Wolpert, Grana, Tracey, Kohler, and Kolchinsky, 2017).

It is this recursive loop of information input, processing, and decision making which creates a feedback loop that eventually leads to the development of complex organizational structures (Figure 1). This process does not constitute an inevitable trajectory towards increasingly complex societies (see works such as Service, 1962). The creation, perpetuation or disbandment of complex structures should rather be seen as a series of steps, which can be ordered in a dual trajectory, consisting of a 'fast' process of opportunistic decision-making through collective action, feeding a second, 'slow' process of socio-political development or decay (Cioffi-Revilla, 2005). The loop is induced by social groups reacting to situational events, which can be highly variable in nature, including human or environmentally induced stresses, opportunities, endogenous and exogenous processes.

At every step of the loop, adaptation can be successful or fail, resulting in development or decay of social organisation. It is clear that complexity is not a given but needs to be continuously developed and maintained. With every iteration of the loop, subsequent strategies and solutions are superimposed. As social organization is maintained, a costly organizational apparatus develops, consisting of multiple and partially overlapping and interconnected structures of administration, laws, social norms and values, all of which are costly to maintain, both in energy and capital investment.

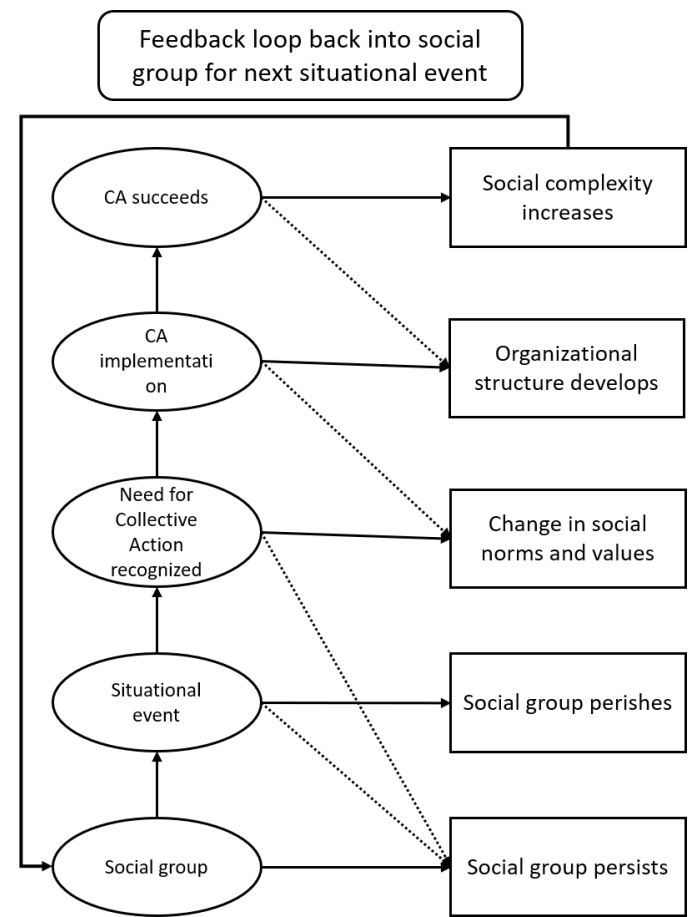

Figure 1. Recursive loop of complexity development (adapted from Cioffi-Revilla, 2005

\section{Materialising complexity}

The theoretical approaches highlighted above can be used as a general framework to trace processes of community formation and dynamics of social complexity. How can we now relate this framework to the archaeological record, given that we cannot directly observe the dynamics of societies in the past?

To start with, we can go back to the social interactions that form the constituent components of social complexity. All interactions inherently have a temporal, spatial, and social dimension, as they take place at a given time and place, and within a certain social framework. For example, a settlement can be considered to largely reflect the actions and practices of the community it housed (Robb, 2007; Smith, 2003). In this sense, a settlement can be seen as a 'pocket of interaction' where, given generally higher population numbers and density, an increased amount of social interactions occurs compared to the surrounding areas (Southall, 1973). Archaeologists have, among others, applied this insight to develop measures to calculate absolute population numbers of settlements through the abandoned material residues of these people and their practices (Berrey, 2018).

Communities thus form temporally, spatially and socially defined 'locales', in which specific sets of interactions and practices are manifested (Giddens, 1984). For example, the practice of exchange will often be concentrated in a specifically designated market place. Repeated performance within such contexts, induces structuration of a set of interactions and practices and determines how space is used for human activities to provide the context of social life. This repetition effectively transforms space into 'place', or 'lived space', ascribing meanings, identities and memories that actively shape people's daily practices and experiences 
(Feld and Basso, 1996, Low and Lawrence-Zúñiga, 2003. Rodman, 1992). From this perspective, a mutually constituting relationship can be proposed between settlement form and the actions and interactions of heterogeneous individuals, groups, and institutions, each with their own motivations and identities (Fisher and Creekmore, 2014).

This is all highly relevant for archaeologists, as it essentially allows material environments to be analysed, not only as invariant contexts for social action and interaction, but as inherently reflecting the nature and intensity of these processes, and thus provides a way to connect the static archaeological record with the dynamics of the society which produced it. This approach can be supplemented with a model of material environment-behaviour interactions (Rapoport, 1988), identifying three levels of material communication and information transfers: 1) low-level meaning focusing on mnemonic cues for identifying the uses for which certain material settings are intended, enabling users of a certain place to behave and act appropriately and predictably; 2) middle-level meaning communicating deliberate statements about identity, status, wealth, power, etc.; 3) high-level meaning as a symbolic representation that only exists within the context of a specific cultural and religious system.

The approach also includes material objects. Through repeated usage, objects are 'enchained' in interlinked sets that are structured spatially and temporally, thus creating distinct and circumscribed contexts pulling together sets of material linkages to constitute social practices in which these objects are 'proper' to be used (Lucas, 2012). In very much the same way, one reserves the fancy set of tableware for special dinner parties rather than for your everyday meal. In this sense, material culture itself should be considered as an information transmission device (Clarke, 1968). For example, it has been suggested that diversity in material culture can be directly linked to its functionality as an information transmitter through its role as regulator in managing cognitive limits to information processing (Kohler, Van Buskirk, and Ruscavage-Barz, 2004, Nelson et al., 2011).

The importance of diversity in material culture can be linked back to the model of recursive feedback loops highlighted earlier, where social complexity can effectively be considered a 'problem-solving tool' (Tainter, 1996). The information processing and decision-making strategies behind this process are built around three general mechanisms of change: 1) diversification, 2) connectivity, 3) specialization (Tainter, 1996, p. 64). Complexity is built up through repeated combination of these mechanisms. Diversification - for example in the usage of natural resources and capital, or in social rules, functions, roles, etc. - increases system robustness and resilience (Folke, 2006) and aids recovery from disturbance events (Page, 2010).

At the same time, structurally differentiated components must also be integrated in order for the system to function. Connectivity between components is what makes a complex system truly "tick". It has for example been suggested that the long-term evolution of complexity mainly entails the development of institutions that integrate sub-units together in a coordinated manner in political, economic, and social networks (Currie et al., 2016).
An essential element of connectedness also pertains to the intensity of its linkages (Rosen and Rivera-Collazo, 2012) and is determined by the degree of specialization in capital and energy investment towards a specific outcome. Specialization typically induces multiplier effects yielding increasing returns to scale (Arthur, 2015), as has for example been suggested for the parallel development of Sagalassos as a specialized pottery production centre and urban community (Daems and Poblome, 2016, Poblome et al., 2013).

Of course, complexity cannot continue to increase indefinitely. Increasing complexity is subjected to trade-offs between costs and benefits, and subjected to marginal returns on investment, making it harder to sustain complex organizational structures while maintaining efficiency. Increasing specialization induces a resilience trade-off where the increased efficiency of the system also entails increased rigidity, hampering the system's ability to overcome disturbance event such as climatic changes, natural disasters, and abrupt shifts in socio-political structures (Gunderson and Holling, 2002). It is precisely in the deep-time study of complexity trajectories, assessing the long-term effects of mechanisms of complexity development and all associated trade-offs in system organization, that the power of archaeology lies.

\section{Conclusions}

Despite the limited amount of space, we have covered quite some ground in this paper. Starting on the micro-scale with ordinary day-to-day interactions between people, and concluding with the costs and risks of complexity in the face of large disturbance events. This paper has tried to provide a logical sequence going from social interactions to the development of complex organizational structures, and suggest a way to contextualize this process within an explanatory framework based on the material properties of the archaeological record and complex systems thinking.

This is by no means claimed to be the one and only key to unlock the complexities of past societies. Still, it offers way forward that could hold great potential for the future development of archaeology. Archaeologists have in recent years started to open up to such approaches, resulting in increasingly interdisciplinary collaborations and applications of a variety of concepts, methods and tools derived from complex systems thinking. It can only be to the benefit of our discipline.

\section{Acknowledgements}

The author wishes to thank Sergi Valverde and Simon Carrignon for organizing the wonderful sessions at CCS 2017 and 2018, and for their suggestions in submitting this paper. Gratitude is also due to Jeroen Poblome of the Sagalassos Project for his encouragement to pursue the approaches discussed in this paper and for providing critical reflections on this work. The author has been part of the Sagalassos Archaeological Research Project, originally directed by Marc Waelkens and since 2014 under directorship of Jeroen Poblome (both KU Leuven).

\section{Funding}

The research for this paper was funded through a fellowship by the Research Foundation Flanders (FWO), and has further been 
supported by the Belgian Programme on Interuniversity Poles of Attraction, the Research Fund of the University of Leuven, and the Academische Stichting Leuven

\section{Declaration of conflicting interests}

The Author declares that there is no conflict of interest.

\section{Author bio}

Dries Daems is part of the Sagalassos Archaeological Research Project (Leuven, Belgium). In 2018, he obtained his Ph.D. at the KU Leuven. He is currently postdoctoral fellow at the Suna \& Inan Kıraç Research Centre for Mediterranean Civilizations (Antalya, Turkey). $\mathrm{He}$ is also founding member of the SuRP+ research consortium at the KU Leuven. His research interests include social complexity and community formation, the origin of polis in southwest Anatolia, human-environment interactions and agent-based modelling.

\section{References}

Arthur, B. (2015). Complexity and the economy. Oxford: Oxford University Press.

Auban, J., Martin, A., \& Barton, C. (2013). Complex systems, social networks, and the evolution of social complexity in the east of spain from the neolithic to pre-roman times. In M. Berrocal, L. Sanjuán, \& A. Gilman (Eds.), The prehistory of iberia: Debating early social stratification and the state. New York: Routledge.

Axelrod, R. (1984). The evolution of cooperation. New York: Basic Books.

Bentley, A., \& Maschner, H. (2003). Complex systems and archaeology. Salt Lake City: Utah University Press.

Berrey, A. (2018). Making absolute population estimates in the intermediate area using the area and density of ceramic sherd scatters: An application of regression analysis. Journal of Archaeological Science, 97, 147158. doi $10.1016 /$ j.jas.2018.07.008

Bettencourt, L. (2013). The origins of scaling in cities. Science, 340(6139), 1438-1441. doi 10.1126/science. 1235823

Bettencourt, L., Lobo, J., \& Strumsky, D. (2007). Invention in the city: Increasing returns to patenting as a scaling function of metropolitan size. Research Policy, 36(1), 107-120. doi:10.1016/j.respol.2006.09.026

Blanton, R. E., \& Fargher, L. F. (2016). How humans cooperate: Confronting the challenges of collective action. Boulder: University Press of Colorado.

Chapman, R. (2003). Archaeologies of complexity. London: Routledge.

Cioffi-Revilla, C. (2005). A canonical theory of origins and development of social complexity. The Journal of Mathematical Sociology, 29(2), 133-153. doi:10 . 1080/00222500590920860

Clarke, D. L. (1968). Analytical archaeology. London: Methuen.
Currie, T., Turchin, P., Bednar, J., Richerson, P., Schwesinger, G., Steinmo, S., ... Wallis, J. (2016). Evolution of institutions and organizations. In D. S. Wilson \& A. Kirman (Eds.), Complexity and evolution: Toward a new synthesis for economics (pp. 201-238). doi $10.7551 /$ mitpress/9780262035385. 001.0001

Daems, D., \& Poblome, J. (2016). Adaptive cycles in communities and landscapes: The case of sagalassos and düzen tepe during the classical/hellenistic period. Archaeological Review from Cambridge, 31(2), 91107.

Dubreuil, B. (2010). Human evolution and the origins of hierarchies: The state of nature. Cambridge University Press.

Dunbar, R. I. M. (1993). Coevolution of neocortical size, group size and language in humans. Behavioral and Brain Sciences, 16(4), 681-694. doi 10.1017/ S0140525X00032325

Feld, S., \& Basso, K. H. (1996). Senses of place. Santa Fe: School of American Research Press.

Fisher, K. D., \& Creekmore, A. (2014). Making ancient cities: New perspectives on the production of urban spaces. In A. Creekmore \& K. D. Fisher (Eds.), Making ancient cities: Space and place in early urban societies (pp. 1-31). New York: Cambridge Cambridge University Press.

Fletcher, R. (1995). The limits of settlement growth : A theoretical outline. Cambridge: Cambridge University press.

Folke, C. (2006). Resilience: The emergence of a perspective for social-ecological systems analyses. Global Environmental Change. Resilience, Vulnerability, and Adaptation: A Cross-Cutting Theme of the International Human Dimensions Programme on Global Environmental Change, 16(3), 253-267. doi:10.1016/ j.gloenvcha.2006.04.002

Freeberg, T. M., Dunbar, R. I. M., \& Ord, T. J. (2012). Social complexity as a proximate and ultimate factor in communicative complexity. Philosophical Transactions of the Royal Society B: Biological Sciences, 367(1597), 1785-1801. doi:10.1098/rstb . 2011.0213

Giddens, A. (1984). The constitution of society: Outline of the theory of structuration. Berkeley: University of California Press.

Gunderson, L. H., \& Holling, C. S. (2002). Panarchy: Understanding transformations in human and natural systems. Washington, DC: Island Press.

Johnson, G. A. (1982). Organizational structure and scalar stress. In C. Renfrew, M. Rowlands, \& B. Segraves (Eds.), Theory and explanation in archaeology, Cambridge: Academic Press.

Kohler, T., Van Buskirk, S., \& Ruscavage-Barz, S. (2004). Vessels and villages: Evidence for conformist transmission in early village aggregations on the pajarito plateau, new mexico. Journal of Anthropological Archaeology, 23(1), 100-118. doi:10.1016/j.jaa.2003. 12.003 
Kohring, S., \& Wynne-Jones, S. (2007). Socialising complexity: Structure, interaction and power in archaeological discourse. Oxford: Oxbow Books.

Lewin, R. (1992). Complexity: Life at the edge of chaos. Chicago: University of Chicago Press.

Low, S. M., \& Lawrence-Zúñiga, D. (2003). Anthropology of space and place: Locating culture. Wiley.

Lucas, G. (2012). Understanding the archaeological record. Cambridge: Cambridge University Press.

Mitchell, M. (2009). Complexity: A guided tour. Oxford; New York: Oxford University Press.

Nelson, M., Hegmon, M., Kulow, S., Peeples, M., Kintigh, K., \& Kinzig, A. (2011). Resisting diversity: A longterm archaeological study. Ecology and Society, 16(1). doi: $10.5751 /$ ES-03887-160125

Ortman, S., Cabaniss, A., Sturm, J., \& Bettencourt, L. (2015). Settlement scaling and increasing returns in an ancient society. Science Advances, 1(1).

Ortman, S. G., Davis, K. E., Lobo, J., Smith, M. E., Bettencourt, L. M. A., \& Trumbo, A. (2016). Settlement scaling and economic change in the central andes. Journal of Archaeological Science, 73, 94-106. doi: $10.1016 /$ j.jas.2016.07.012

Page, S. E. (2010). Diversity and complexity. Princeton: Princeton University Press.

Poblome, J., Braekmans, D., Waelkens, M., Firat, N., Vanhaverbeke, H., Martens, F., ... Degryse, P. (2013). How did sagalassos come to be? a ceramological survey. In M. Tekocak (Ed.), Studies in honour of $k$. levent zoroğlu (pp. 527-540). Antalya: Suna \& Inan Kiraç Research Institute on Mediterranean Civilizations.

Rapoport, A. (1988). Levels of meaning in the built environment. In F. Poyatos (Ed.), Cross-cultural perspectives in nonverbal communication (pp. 317336). Toronto: Hogrefe.

Robb, J. (2007, July 23). The early mediterranean village: Agency, material culture, and social change in neolithic italy. Cambridge ; New York: Cambridge University Press.

Rodman, M. C. (1992). Empowering place: Multilocality and multivocality. American Anthropologist, 94(3), 640-656. doi:10.1525/aa.1992.94.3.02a00060

Rosen, A. M., \& Rivera-Collazo, I. (2012). Climate change, adaptive cycles, and the persistence of foraging economies during the late pleistocene/holocene transition in the levant. Proceedings of the National Academy of Sciences, 109(10), 3640-3645. doi:10 . 1073/pnas.1113931109

Sanderson, S. K. (1999). Social transformations: A general theory of historical development. Totowa: Rowman \& Littlefield.

Service, E. R. (1962). Primitive social organization: An evolutionary perspective. New York: Random House.

Smejda, L., \& Baumanova, M. (2015). Conceptual crossroads: Community and society in prehistory. In $\mathrm{K}$. Kristiansen, L. Smejda, \& J. Turek (Eds.), Paradigm found: Archaeological theory - present, past and future. essays in honour of evzen neustupny (pp. 4760). Oxford: Oxbow Books.
Smith, A. T. (2003, October 7). The political landscape: Constellations of authority in early complex polities. Berkeley: University of California Press.

Southall, A. W. (1973). Urban anthropology: Cross-cultural studies of urbanization. New York: Oxford university press.

Tainter, J. (1996). Complexity, problem solving and sustainable societies. In R. Costanza, O. Segura, \& J. Martinez-Alier (Eds.), Getting down to earth: Practical applications of ecological economics (pp. 61-76). Washington DC: Island Press.

Turchin, P., Currie, T. E., Whitehouse, H., François, P., Feeney, K., Mullins, D., ... Spencer, C. (2017). Quantitative historical analysis uncovers a single dimension of complexity that structures global variation in human social organization. Proceedings of the National Academy of Sciences. doi:10.1073/pnas. 1708800115

Turner, J. (2003). Human institutions: A theory of societal evolution. Totowa: Rowman \& Littlefield,

Wolpert, D., Grana, J., Tracey, B., Kohler, T., \& Kolchinsky, A. (2017). Modeling social organizations as communication networks. arXiv:1702.04449 [physics]. arXiv: 1702.04449 